\title{
ПЕРСПЕКТИВЫ ТИПИЗАЦИИ ЗАПАСОВ УГЛЕЙ ДЛЯ ЕДИНОГО УЧЕТА
}

\author{
Охотников Константин Владимирович, \\ Oxotnikow@mail.ru \\ Национальный исследовательский Томский политехнический университет, \\ Россия, 634050, Томск, ул. Ленина, 30.
}

\begin{abstract}
Актуальность. Исследование проблем и существующих предпосылок в создании единого учета угольной массы в виде запасов в недрах, сырья при добыче и товара при реализации показало допустимость решения данной задачи. Единый учёт позволит достоверно оценивать ресурсный потенциал угольных бассейнов и отдельных недропользователей, делая его открытым и понятным для международных инвестиций. С другой стороны, устраняется несогласованность в государственном регулировании налогообложения за пользование недрами.

Цель: предложить подход к формированию единой классификации углей для типизации запасов.

объекты: месторождения каменного, бурого угля и антрацита. Апробация проводилась на углях разного марочного состава действующих участков угольной компании «Ресурс», расположенных в Ерунаковском, Прокопьевско-Киселевском геологоэкономических районах. Предлагаемый подход опирается на существующую нормативную базу стандартов стран СНГ, в частности ГОСТ 25543-2013.

Методы: сравнительный анализ существующих подходов классифицирования углей, применение марок, технологических групп и направления использования как критериев для типизации запасов.

Результаты. Показана проблема понимания глубокой переработки как критерия оценки ценности углей, необходимость внесения данного критерия в виде требования для правильного проведения геологоразведочных работ, направленных на выявление и оконтуривание углей с различными технологическими свойствами. Данный критерий, наряду с другими показателями ценности угольного сырья, необходим для деления углей по типам в зависимости от глубокой их переработки. Даны рекомендации по ранжированию углей на основе технологических групn, и представлена типизация запасов углей. Дифрференциация угольных запасов по направлениям использования углей, как критерий оценки, обеспечивает правильное обоснование и проектирование разведки в границах лицензионного участка.
\end{abstract}

Ключевые слова:

Бурые угли, каменные угли, антрациты, типизация, марки, бренды, налогообложение, критерии ценности.

\section{Введение}

На мировом рынке в настоящее время сложилась неблагоприятная обстановка, связанная с устойчивым падением цен на уголь. У большинства отечественных добывающих компаний это обстоятельство приводит к значительному экономически неоправданному снижению себестоимости угольной продукции.

Отметим, что эти проблемы коснулись не всех участников рынка, поэтому указанные трудности поразному отразились на экономике угледобывающих предприятий. В частности, угольные компании, которые добывают востребованные технологические, коксующиеся угли либо отгружают подготовленную угольную продукцию с высокими показателями качества, не так остро ощутили изменения цены и спроса на свою продукцию $[1,2]$.

Получается, что рынок стимулирует производителей угля реализовывать ценное угольное сырье с выдержанным качественным составом при наличии таковых в недрах, а при их отсутствии готовить ликвидную угольную продукцию с заданными параметрами качества. В мире на биржевых площадках идет торговля брендами, под которыми понимается определенный набор качественных характеристик, а также, как правило, привязка к географическому объекту, угольной компании. А это значит, что в ценообразовании учувствуют репутационные риски, надежность качественной продукции, понимание объёмов затрат на глубокую переработку.
Конечно, отечественные компании, прежде чем стать участником международной торговли, проходят международные оценки разными методами: JORC, CRIRSCO и другие. По ним выявляются слабые места в ресурсной обеспеченности предприятия устойчивым качеством товара. В связи с этим возникает вопрос: почему наша государственная система внутренней оценки угольного сырья не способна выявить его ценность, определить уголь в соответствии с международной номенклатурой, выступить в качестве организатора единого учета углей для недр, налогов, биржи?

Проблема вполне очевидна - нет критериев ценности угольного сырья и единого подхода к созданию классификаций, определяющих направления использования углей (табл. 1). Несогласованность существующих классификаций освещалась в разных геологических изданиях [3-7], но обозначенная проблема затрагивает существующую типизацию запасов.

Рассмотрим основные подходы к классификации углей, представленные в табл. 1. Основным классификатором разделения углей по маркам является ГОСТ 25543-2013 [8], а с 2011 г. он ещё стал регулятором ценности углей, т. к. на него опирается классификация углей по налогообложению. Видно, что существующие классификации для разделения углей в различных системах учета имеют ряд несоответствий.

Во-первых, не согласуются марки в рекомендуемых направлениях использования ГОСТ 25543-2013. Более того, сами направления использования звучат 
некорректно, например, что за направление «производство строительных материалов» или «прочие».

Во-вторых, отсутствуют основания для выделения в классификации по налогам вида «уголь за исключе- нием антрацита, коксующегося, бурого, ценные коксующиеся», и это не согласуется с рекомендуемыми ГОСТ 25543 направлениями использования.

Таблица 1. Классификация углей

Table 1. Coal classification

\begin{tabular}{|c|c|c|c|c|c|c|c|c|c|c|}
\hline $\begin{array}{l}\text { Вид система- } \\
\text { тизации } \\
\text { Type of } \\
\text { systematization }\end{array}$ & ГОСТ (SS) 255 & 543-2013 & $\begin{array}{r}\text { Постано } \\
\text { о налоI } \\
\text { Tax Ord }\end{array}$ & $\begin{array}{l}\text { вление } \mathrm{N} \\
\text { сообложе } \\
\text { inance } \mathrm{No}\end{array}$ & $\begin{array}{l}429 \\
429\end{array}$ & $\begin{array}{r}\text { Государст } \\
\text { баланс за } \\
\text { State balance }\end{array}$ & $\begin{array}{l}\text { венный } \\
\text { пасов } \\
\text { of stocks }\end{array}$ & $\begin{array}{r}\text { Пред } \\
\text { S }\end{array}$ & лагаемая тип & $\begin{array}{l}\text { Iизация } \\
\text { ing }\end{array}$ \\
\hline $\begin{array}{c}\text { Критерии } \\
\text { деления } \\
\text { Division } \\
\text { criteria }\end{array}$ & \begin{tabular}{|c|} 
По направле- \\
ниям исполь- \\
зования \\
By directions \\
of use \\
\end{tabular} & $\begin{array}{l}\text { Марка } \\
\text { Mark }\end{array}$ & $\begin{array}{c}\text { Вид угля } \\
\text { Туре of coal }\end{array}$ & $\begin{array}{l}\text { Марка } \\
\text { Mark }\end{array}$ & $\begin{array}{l}\text { Налого- } \\
\text { вая } \\
\text { ставка } \\
\text { Tax rate }\end{array}$ & $\begin{array}{l}\text { Виды запасов } \\
\text { Kind of stocks }\end{array}$ & $\begin{array}{l}\text { Марка } \\
\text { Mark }\end{array}$ & $\begin{array}{c}\text { Типы } \\
\text { запасов } \\
\text { Stock types }\end{array}$ & $\begin{array}{l}\text { Марка } \\
\text { Mark }\end{array}$ & $\begin{array}{l}\text { Технологи- } \\
\text { ческие } \\
\text { группы } \\
\text { Technology } \\
\text { groups }\end{array}$ \\
\hline \multirow{7}{*}{$\begin{array}{l}\text { Наименова- } \\
\text { ние позиций } \\
\text { Name of } \\
\text { positions }\end{array}$} & \multirow{2}{*}{$\begin{array}{l}\text { Коксование } \\
\text { Coking }\end{array}$} & \multirow{2}{*}{\begin{tabular}{|l} 
ДГ, Г, \\
ГЖО, \\
ГЖ, Ж, \\
КЖ, К, \\
КО, \\
КСН, \\
КС, \\
ОС, ТС
\end{tabular}} & \multirow{2}{*}{\begin{tabular}{|l} 
Уголь \\
коксую- \\
щийся \\
Coking coal \\
\\
\end{tabular}} & \multirow{2}{*}{$\begin{array}{l}\text { ГЖО, } \\
\text { ГЖ, Ж, } \\
\text { КЖ, К, } \\
\text { КО, КС, } \\
\text { ОС }\end{array}$} & \multirow{2}{*}{57} & \begin{tabular}{|l|} 
ценные \\
коксующиеся \\
valuable \\
coking \\
\end{tabular} & $\begin{array}{l}\text { ГЖ, Ж, } \\
\text { КЖ, К, } \\
\text { OC }\end{array}$ & $\begin{array}{l}\text { коксообра- } \\
\text { зующие } \\
\text { coke- } \\
\text { forming } \\
\end{array}$ & $\begin{array}{c}\text { ГЖ, Ж, } \\
\text { КЖ, К, КО, } \\
\text { ОС }\end{array}$ & $\begin{array}{c}1 \Gamma Ж, 2 Г Ж, \\
2 Ж, \text { КЖ, 1К, } \\
2 \mathrm{~K}, 1 \mathrm{KO}, \\
2 \mathrm{KO}, 1 \mathrm{OC}\end{array}$ \\
\hline & & & & & & $\begin{array}{l}\text { коксующиеся } \\
\text { coking }\end{array}$ & $\begin{array}{c}\text { ДГ, Г, } \\
\text { ГЖО, } \\
\text { КСН, КО, } \\
\text { ТС, СC } \\
\end{array}$ & \multirow[t]{2}{*}{$\begin{array}{l}\text { технологи- } \\
\text { ческие } \\
\text { technolo- } \\
\text { gical }\end{array}$} & \multirow[t]{2}{*}{$\begin{array}{c}\Gamma, \text { ГЖО, Ж, } \\
\text { КС, ОС, А }\end{array}$} & \multirow{2}{*}{ 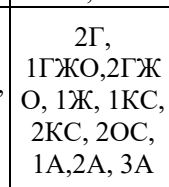 } \\
\hline & \multirow{3}{*}{\begin{tabular}{|l} 
Технологиче- \\
ские и энер- \\
гетические \\
цели \\
Technological \\
and energy \\
goals \\
\end{tabular}} & \multirow{3}{*}{$\begin{array}{c}\text { Б, Д, } \\
\text { СC, Т, } \\
\text { A }\end{array}$} & \multirow{2}{*}{$\begin{array}{l}\text { Антрацит } \\
\text { Anthracite }\end{array}$} & \multirow{2}{*}{ A } & \multirow{2}{*}{47} & & \multirow[t]{2}{*}{ A } & & & \\
\hline & & & & & & & & \multirow[b]{2}{*}{$\begin{array}{l}\text { энерготех- } \\
\text { нологиче- } \\
\text { ские } \\
\text { energy } \\
\text { technology } \\
\end{array}$} & \multirow[b]{2}{*}{$\begin{array}{c}\text { Б, Д, ДГ, Г, } \\
\text { КСН, ТС, } \\
\text { СС, Т }\end{array}$} & \multirow[b]{2}{*}{ 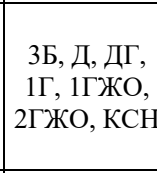 } \\
\hline & & & \multirow{2}{*}{\begin{tabular}{|l|} 
Уголь, за \\
исключени- \\
ем антраци- \\
та, угля \\
коксующе- \\
гося и угля \\
бурого \\
Coal, \\
excluding \\
anthracite, \\
coking coal \\
and brown \\
coal \\
\end{tabular}} & \multirow[b]{2}{*}{$\begin{array}{c}\text { Д, ДГ, } \\
\Gamma, \text { КСН, } \\
\text { ТC, СС, } \\
\text { Т }\end{array}$} & \multirow[b]{2}{*}{24} & \multirow[b]{2}{*}{$\begin{array}{l}\text { энергетиче- } \\
\text { ские energy }\end{array}$} & \multirow[b]{2}{*}{$\begin{array}{c}\text { Д, ДГ, Г, } \\
\text { ГЖО, } \\
\text { КСН, КО, } \\
\text { ТC, СС, Т }\end{array}$} & & & \\
\hline & \multirow[t]{2}{*}{$\begin{array}{l}\text { Производство } \\
\text { строительных } \\
\text { материалов и } \\
\text { прочие } \\
\text { Production of } \\
\text { building } \\
\text { materials and } \\
\text { other }\end{array}$} & $\begin{array}{l}\text { Б, Д, } \\
\text { ДГ, Г, } \\
\text { ГЖО, } \\
\text { ГЖ, Ж, } \\
\text { К, } \\
\text { КСН, } \\
\text { КС, }\end{array}$ & & & & & & \multirow[t]{2}{*}{$\begin{array}{l}\text { топливные } \\
\text { fuel }\end{array}$} & \multirow[t]{2}{*}{$\begin{array}{c}\text { Б, Д, ДГ, Г, } \\
\text { КСН не } \\
\text { удовлетво- } \\
\text { ряют глу- } \\
\text { бокой } \\
\text { переработке } \\
\text { do not } \\
\text { satisfy deep } \\
\text { processing }\end{array}$} & \multirow{2}{*}{$\begin{array}{c}\text { 1Б, 2Б, TC } \\
\text { CC, T }\end{array}$} \\
\hline & & $\mathrm{TC}, \mathrm{CC}$ & \begin{tabular}{|l|} 
Уголь \\
бурый \\
Brown coal \\
\end{tabular} & Б & 11 & $\begin{array}{l}\text { Бурые } \\
\text { brown }\end{array}$ & Б & & & \\
\hline
\end{tabular}

Такой порядок не понятен за рубежом, и международные инвесторы вынуждены проводить международную оценку каждого предприятия. Таким образом, очевидно, что давно назрела острая необходимость в создании универсальной классификации для единого учета угля. По мнению автора, основным критерием ценности для углей должно стать направление их использования для глубокой переработки.

В международной практике в основе деления углей лежит дифференциация по типам переработки: hardcockingcoal (HCC), semi-softcockingcoal (SSCC), pulverizedcoalforinjection (PSI), thermalcoal. По этому критерию они становятся товарными брендами с узкими колебаниями определяющих для глубокой переработки значимых параметров качества угля [9]. Например, в табл. 2 показаны некоторые бренды и их параметры на рынке углей Австралии.

Из неё видно, что введение новой классификации твердых полезных ископаемых (ТПИ) при существующей несогласованности классификаций, ГОСТ 25543 с налогами на добычу полезных ископаемых (НДПИ) и Государственным балансом запасов (ГБЗ), а также отсутствие единого критерия ценности - направления использования углей - добавит противоречий в понимании угольных запасов, но главное обострит взаимоотношения между государством и недропользователем.

Таблица 2. Мировая практика торговли брендами углей на примере Австралии [10]

Table 2. World practice of trade in coal brands on the example of Australia [10]

\begin{tabular}{|l|c|c|c|}
\hline \multicolumn{1}{|c|}{ Бренд/Brand } & HCC & SSCC & PSI \\
\hline Зола/Ash, \% & 10,5 & 9,25 & 8,5 \\
\hline GAD, ккал/кг & - & - & 7800 \\
\hline HGI & - & - & 78 \\
\hline CSR,\% & 74 & - & - \\
\hline Летучие/Volatile VM, \% max & 20,7 & 34 & 13 \\
\hline Влага/Moisture, TM & 9,5 & 9,5 & 10 \\
\hline Сера/Sulfur, \% max & 0,6 & 0,58 & 0,55 \\
\hline Фосфор/Phosphorus, \% max & 0,03 & 0,025 & - \\
\hline Фиксированный углерод/Fixed carbon, \% & - & 53 & - \\
\hline Общий углерод/Carbon, \% & - & - & 90,5 \\
\hline Макс текучесть/Maximum fluidity & 400 & 200 & - \\
\hline Индекс свободного вспучивания CSN/FSI & 8,5 & 5,5 & - \\
\hline Витринит/Vitrinit, \% & 71 & - & - \\
\hline Во, тах & 1,42 & - & - \\
\hline Крупность/Соаrseness, мм max & 50 & - & - \\
\hline
\end{tabular}


В современных условиях единственное, на что ориентируется продавец угля, - это контракты и договора с установленными ограничениями по показателям качества. Как это сделать, чтобы соответствовать государственному учету? Он вынужден подстраиваться различными доступными способами.

По мнению автора, решение проблемы должно идти по двум направлениям. Первое - это выверенная и надёжная оценка полезного ископаемого в недрах. Для этого необходимо пересмотреть основные принципы ведения геологоразведочных работ на угольных месторождениях, которые представляют собой раскройку в виде лицензионных участков. Оценка свойств и качества углей пластов больше нацелена на получение высоколиквидного товара.

Второе - решить проблему по вводу критериев ценности и параметров углей в недрах, и один из них - это направление использования углей для глубокой переработки, обусловливающий типизацию запасов. Только ввод целевых параметров, определяющих однозначную принадлежность к конкретному направлению глубокой переработки, гарантирует правильное дифференцирование углей и применение ценности запасов в качестве инвестиционного инструмента.

Создание системы учета запасов каменного угля является продолжением развития методической базы угольной отрасли. За прошедший период многочисленными советскими институтами создавались методики исследований, государственные стандарты и классификации по углям, которые ориентировались на угли конкретных бассейнов [11]. Создание бассейновых стандартов для установления направления использования углей в современных условиях стали источником их несогласованности по типизации углей, например, появились энерготехнологические угли (Печорский и Восточные бассейны), но они почему-то не выделены в Кузбассе наряду с коксующимися и энергетическими углями [12].

Ранее ГОСТ 8162-79 объединял бассейновые стандарты для выделения коксующихся углей и являлся главным для определения направления использования в сравнении с другими стандартами. В настоящее время угли гумусового происхождения также систематизированы по маркам (ГОСТ 25543), но дополнительно выделяются технологические группы и подгруппы. Разработчики стандарта предполагали, что марки способны отражать однотипность углей в классификации, образуя чёткую систему для понимания и использования, а в целом отражать уровень унификации углей для учёта запасов, переработки (сырьевая угольная база) и налогообложения (экономический учёт за пользование недрами) [13].

Практика показала, и это отмечено многими учёными [7, 14-16, 20], что ГОСТ 25543 оказался в этой части не доработан и по маркам рекомендуемые направления использования углей не всегда соответствуют реальным условиям рынка. Обоснованно установлено, что это является скрытой причиной несовершенства методического обеспечения геологоразведочных работ $[17,18]$.
Отметим, что в работах $[3-7,14,18]$, авторы опирались на особенности условий образования углей. Исходя из этого были предопределены основные виды глубокой переработки:

1) коксование (слоевое и кусковое);

2) металлургическое производство (пылеугольное топливо (ПУТ), восстановление);

3) индустрия и энергогенерация (неметаллургическое производство, электростанции);

4) топливное хозяйство (коммунальный сектор).

Видно, что выявление технологических свойств, в частности коксуемости, и коксующей способности является приоритетным по отношению к другим свойствам. В связи с этим необходимы критерии ценности и параметры для выделения среди коксующихся углей: коксообразующих и технологических углей, среди энергетических углей - энерготехнологических и топливных углей. Для этого задействуются существующие параметры деления углей по классу, типу и подтипу и на их основе предлагается следующий подход унификации углей для типизации запасов. Но основной упор при ранжировании углей для указанной цели делается на их деление по технологическим группам (табл. 3).

Таблица 3. Ограничительные величины для типизации запасов

Table 3. Limit values for typing coal reserves

\begin{tabular}{|c|c|c|c|c|}
\hline $\begin{array}{l}\text { Класс } \\
\text { Class, } \\
R_{0}, \%\end{array}$ & $\begin{array}{c}\text { Тип } \\
\text { Type, } \\
V^{\text {daf }}, \%\end{array}$ & $\begin{array}{c}\text { Подтип } \\
\text { Subtype, } \\
y, \text { мм }\end{array}$ & $\begin{array}{c}\text { Tехнологиче- } \\
\text { ские группы } \\
\text { Technology } \\
\text { groups }\end{array}$ & $\begin{array}{l}\text { Марочный состав } \\
\text { запасов } \\
\text { Brand composition } \\
\text { of stocks }\end{array}$ \\
\hline $\begin{array}{l}08-10 \\
11-14\end{array}$ & $\begin{array}{l}30-36 \\
20-30\end{array}$ & $\begin{array}{c}18-26 \\
10 \text { и } \\
\text { выше }\end{array}$ & $\begin{array}{c}1 \Gamma Ж, 2 Г Ж, \\
2 Ж, \mathrm{~K}, 1 \mathrm{~K}, \\
2 \mathrm{~K}, 1 \mathrm{KO} \\
2 \mathrm{KO}, 1 \mathrm{OC} \\
\end{array}$ & $\begin{array}{c}\text { Коксующиеся } \\
\text { (коксообразуюшие) } \\
\text { Coke-forming } \\
\text { ГЖ, Ж, КЖ, К, КО, ОС }\end{array}$ \\
\hline $\begin{array}{l}06-07 \\
08-09 \\
11-13 \\
14-19\end{array}$ & $36-40$ & 08-09 & $\begin{array}{c}2 \Gamma, 1 \Gamma Ж О, \\
2 \Gamma Ж \mathrm{O}, 1 Ж, \\
1 \mathrm{KC}, 2 \mathrm{KC} \\
2 \mathrm{OC}\end{array}$ & $\begin{array}{c}\text { Коксующиеся } \\
\text { (технологические) } \\
\text { Technological } \\
\text { Г, ГЖО, Ж, КС, ОС }\end{array}$ \\
\hline $\begin{array}{c}09 \text { и } \\
\text { ниже } \\
10 \text { и } \\
\text { выше }\end{array}$ & & $\begin{array}{c}12 \text { и } \\
\text { ниже }\end{array}$ & $\begin{array}{c}\text { Д, ДГ, } 1 \Gamma, \\
1 Г Ж О, \\
2 Г Ж О, \mathrm{KCH}, \\
\text { TC, } \mathrm{CC}, \mathrm{T}\end{array}$ & \begin{tabular}{|c|}
\multicolumn{1}{|c|}{ Энергетические } \\
Д, ДГ, Г, КСН, ТС, СС, Т \\
- энерготехнологические \\
Energytechnology (зола, \\
cepa, фосфор, азот) \\
- топливныelfuel coal
\end{tabular} \\
\hline
\end{tabular}

В этом случае в коксующихся углях выделяются коксообразующие и технологические угли, а в энергетических углях - энерготехнологические и топливные. При таком подходе класс, тип и подтип углей, по сути, становятся качественными кондициями для деления запасов по типам: коксующиеся и энергетические угли, и группам: коксообразующие, технологические, энерготехнологические и топливные (табл. 4). То есть данные критерии увязываются с основными направлениями глубокой переработки.

Таким образом, применение технологической систематизации показывает путь решения проблемы единого деления углей по направлению глубокой переработки. Решив ее, можно на этой основе разработать требования для проведения геологоразведочных работ, направленных на выявление и оконтуривание углей с различными технологическими свойствами. 
Таблица 4. Номенклатура запасов для учёта [7]

Table 4. Stock inventory for accounting [7]

\begin{tabular}{|l|l|l|}
\hline \multicolumn{1}{|c|}{$\begin{array}{c}\text { Коксующиеся } \\
\text { Coking }\end{array}$} & $\begin{array}{c}\text { Вид запасов } \\
\text { Kind of stock }\end{array}$ & \multicolumn{1}{|c|}{$\begin{array}{c}\text { Энергетические } \\
\text { Energy }\end{array}$} \\
\cline { 1 - 1 } $\begin{array}{l}\text { Коксообразующие } \\
\text { Coke forming }\end{array}$ & $\begin{array}{l}\text { Тип запасов } \\
\text { Type of stock }\end{array}$ & $\begin{array}{l}\text { Энерготехнологические } \\
\text { Energy technology }\end{array}$ \\
\cline { 1 - 1 } $\begin{array}{l}\text { Texнологические } \\
\text { Technological }\end{array}$ & & Tопливные/Fuel \\
\hline
\end{tabular}

Лицензионное районирование угольных залежей отличается от площадного деления, направленного на поиск и выделение ценных коксующихся углей в прошлом столетии. Разведка происходила в следующей последовательности: установление марки на месторождении, затем, по возможности, выделение марочных границ по пластам и только на прилегающих участках прирезки к шахтам или разрезам выделялись технологические группы углей (т. е. сортность) после полузаводского коксования.

Лицензирование участков под разработку - это разделение месторождения для действующих угольных компаний. Здесь также требуется проведение локальной разведки для подтверждения марки одновременно с выделением технологических свойств, которые обусловливают сортность углей.

Отметим, площадная методика разведки не предполагала выделения марочных блоков и технологических групп, потому что её основная задача - марочное районирование месторождений и бассейнов с выделением коксующихся углей для нужд коксохимического производства Министерства черных металлов
СССР. В связи с этим редко выходили на запасы категории В, которые касались в основном коксующихся углей $[19,20]$.

Эти подходы нашли отражение в современной нормативной документации, регламентирующей методику разведки каменных углей с последующим подсчётом запасов. Она не претерпела особых изменений, что стало проблемой частого неподтверждения марочного состава и технологических свойств углей пластов на стадии эксплуатации при движении запасов и переходе ископаемого угля в угольную продукцию и в объект налогообложения [21].

По мнению автора, в методических документах не просматривается алгоритм действий, включающий:

- систематизацию углей по технологическим группам;

- определение количества точек с достоверными данными по результатам предыдущей разведки;

- порядок заложения новых точек в разведочной сети для выделения марочных блоков;

- последовательность их увязки с подсчётными блоками на основе корреляционных связей геологических факторов и маркирующих классификационных параметров, по которым устанавливаются градиенты их изменения в углях пластов по простиранию, падению и в разрезе угленосной толщи.

Вышеизложенное можно обобщить в виде составных частей решения проблемы в создании единого учёта (рисунок).

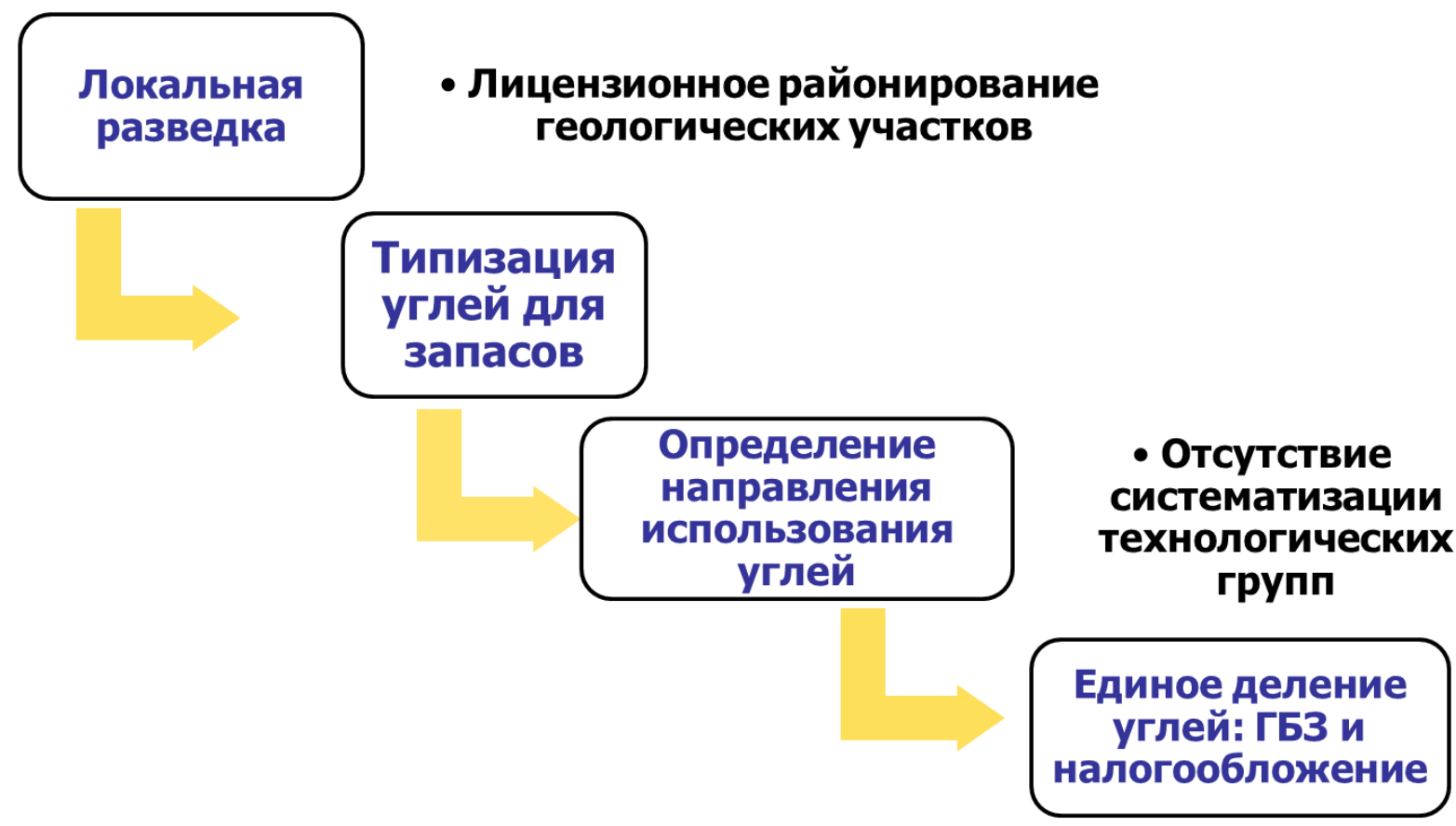

Рисунок. Составные части единого учета углей и проблемь для решения

Figure. Components of a unified coal accounting and problems to solve

\section{Заключение}

Обозначены проблемы, решение которых предлагаемым подходом даёт продвижение по урегулированию производственно-экономических отношений между государством и недропользователем. Данный подход увязывается с новыми требованиями новой классификацией твердых полезных ископаемых в части категорийности запасов и их ранжирования. 
Деление угольных запасов по направлениям использования углей, применяемого как критерия оценки, обеспечивает правильное обоснование и проектирование разведки в границах лицензионного участка.

Выполнение данных условий обеспечит:

- достоверное выделение марочных блоков, а в них установление технологических границ;

- существующий марочный подсчёт запасов, характеризуемый как учёт природных типов углей, опирается на марочные блоки, которые увязываются с категорией геологической изученности,

\section{СПИСОК ЛИТЕРАТУРЫ}

1. Таразанов И.Г., Губанов Д.А. Итоги работы угольной промышленности России за январь-сентябрь 2019 года // Уголь. 2019. - № 12. - C. 40-48.

2. BP Statistical Review of World Energy June 2015 // Coal. - 2015 URL: https://www.resourcedata.org/dataset/rgi-bp-statisticalreview-of-world-energy-2015 (дата обращения: 19.09.2019).

3. Иванов В.П. Промышленно-энергетическая классификация углей для типизации запасов // Недропользование XXI век. 2015. - № 5. - C. 116-123.

4. Иванов В.П., Охотников К.В. Особенности выделения технологических групп в марках при подсчёте запасов углей // Разведка и охрана недр. - 2017. - № 6. - С. 42-48.

5. Иванов В.П. Промышленно-энергетическая классификация для оценки рационального использования углей // Известия вузов. Физика. - 2015. - № 7. - С. 104-111.

6. Bielowicz B.A. New technological classification of low-rank coal on the basis of Polish deposits // Fuel. - 2012. - V. 96. - P. 497-510.

7. Иванов В.П., Торгунаков А.А., Охотников К.В. Роль промышленно-энергетической классификации ископаемых углей в новой классификации геологических запасов ТПИ // Недропользование XXI век. - 2017. - № 6. - С. 104-112.

8. ГОСТ 25543-2013. Угли бурые, каменные и антрациты. Классификация по генетическим и технологическим параметрам. М.: Стандартинформ, 2014. - 18 c.

9. Mazumder B. Coal structure and classification // Coal Science and Engineering. - 2012. - P. 76-99.

10. Specifications guide Metallurgical coal // S\&P Global Platz-2019, November - P. 6. URL: https://www.spglobal.com/platts/ plattscontent/_assets/_files/en/our-methodology/methodologyspecifications/metcoalmethod.pdf (дата обращения 11.12.2019).

11. Методические рекомендации по применению Классификации запасов месторождений и прогнозных ресурсов твёрдых горючих ископаемых. Угли и горючие сланцы. URL: http://gkzrf.ru/sites/default/files/docs/met_rek_tpi_teo_ugli.pdf (дата обращения 19.09.2019). тем самым контролируется степень готовности запасов к проектированию и разработке по группам или отдельным маркам углей.

- предлагаемый учёт запасов по технологическим группам, характеризуемый как учёт сортности углей, позволяет вести учёт движения запасов углей в недрах при формировании сырьевой базы их добычи и переработки и объективного определения объёмов налогов за пользования недрами, что в конечном счёте и есть единый учёт для эффективного освоения недр.

12. Юзвицкий А.З. Методика разведки угольных месторождений Кузнецкого бассейна. - Кемерово: Книжное издательство, 1978. $-235 \mathrm{c}$.

13. Ercegovac M. Genetic-industrial classification of brown coals in Serbia // Int. J. Coal Geol. - 2006. - V. 68. - Iss. 1-2. - P. 39-56.

14. CIM Standing Committee on Reserve Definitions. Adopted by CIM Council, November 14, 2004. URL: http://www.crirsco.com/ cim_definition_standards 2010.pdf (дата обращения 19.09.2019).

15. JORC standard and access to global financial markets. Overview and practical aspects. URL: http://geomar.ru/articles/mineralresources/403-jorc-codex-and-classification-mineralresources.html (дата обращения 19.09.2019).

16. Еремин И.В., Броновец Т.М. Марочный состав углей и их рациональное использование: справочник. - М.: Недра, 1995. $-254 \mathrm{c}$.

17. Охотников К.В., Иванов В.П. Роль опорных точек разведочной сети и достоверность оценки свойств и качества углей пластов // Разведка и охрана недр. - 2018. - № 6. - С. 21-25.

18. Охотников К.В. Влияние классификации угольных запасов на формирование сырьевой базы добывающего предприятия // Кокс и химия. - 2019. - № 9. - С. 8-12.

19. Кодекс Австралазии для составления отчётов о результатах геологоразведочных работ, минеральных ресурсах и рудных запасах (Кодекс JORC). Подготовлен Объединённым Комитетом по Запасам Института Горной Промышленности и Металлургии Австралазии, Австралийским Институтом Наук о Земле и Советом по Полезным Ископаемым Австралазии (JORC). - 2014. URL: https://imcmontan.ru/files/jorc.pdf (дата обращения 19.09.2019).

20. Хрусталёва Г.К., Ерёмин И.В., Броновец Т.М. Качество и направление использования углей. Принципы современной промышленной классификации углей // Угольная база России. - М.: Геоинформмарк, 2004. - Т. 1. - С. 353-357.

21. Mineral Reserves Reporting Standards. URL: http://technology. infomine.com/reviews/ report-ingstandards/welcome.asp?view=full. (дата обращения 11.07.2019).

Поступила 16.01.2020 г.

\section{Информация об авторах}

Охотников К.B., аспирант отделения геологии Инженерной школы природных ресурсов Национального исследовательского Томского политехнического университета. 
UDC 552.574

\title{
PROSPECTS OF COAL RESERVES TYPIFICATION FOR CONSOLIDATED RECORDING
}

\author{
Konstantin V. Ohotnikov, \\ Oxotnikow@mail.ru \\ National Research Tomsk Polytechnic University, \\ 30, Lenin avenue, Tomsk, 634050, Russia.
}

Relevance. Investigation into the issues and existing prerequisites for development of a system of consolidated recording of the bulk of coal in the form of the reserves in place, the mined raw material and the goods to be sold proved the implementability of the task. The consolidated recording will facilitate a proper assessment of the country's resource potential, as well as that of individual mineral developers, making it transparent and comprehensive for international investors. On the other hand, the recording eliminates the discrepancies in the governmental regulation of taxes imposed for the use of subsoil.

The aim of the research is to offer an approach to development of a consolidated classification of coals for the typification of reserves.

Objects: the fields of mineral, brown and anthracite coal. The approbation was performed using coal of different grade compositions mined by «Resurs» Company from the existing mine sites located in Erunakovsky and Prokopievsk-Kiselevsk geological and economic districts. The approach offered is based on the existing regulatory frame work containing the standards used in the CIS countries, including GOST 25543-2013.

Methods: comparative analysis of the existing approaches to coal classification, use of grades, process groups and types of usage as the criteria for typification of reserves.

Results. The paper demonstrates the issues of understanding the advanced processing as the criterion for evaluation of coals and the need to introduce it as a requirement for proper performance of geological prospecting intended to identify and outline the coals having different process properties. The criterion, as well as other indicators of coal value, is required to typify coals depending on the degree of their processing. The paper contains recommendations on rating of coals based on process groups, as well as the typification of coal reserves. The division of coal reserves by areas of coal use, applied as an evaluation criterion, provides the correct justification and design of exploration within the boundaries of the licensed area.

Key words:

Brown coal, mineral coal, anthracite coal, typification, grades, brands, taxation, criteria of value.

\section{REFERENCES}

1. Tarazanov I.G., Gubanov D.A. Itogi raboty ugolnoy promyshlennosti Rossii za yanvar-sentyabr 2019 goda [The results of the coal industry of Russia for January-September 2019]. Coal, 2019, no. 12 , pp. $40-48$

2. BP Statistical Review of World Energy June 2015. Coal, 2015, Available at: https://www.resourcedata.org/dataset/rgi-bpstatistical-review-of-world-energy-2015 (accessed 19 September 2019).

3. Ivanov V.P. Industrial and energy classification of coal for typing reserves. Subsoil use XXI century, 2015, no. 5, pp. 116-123. In Rus.

4. Ivanov V.P., Okhotnikov K.V. Osobennosti vydeleniya tekhnologicheskikh grupp v markakh pri podschete zapasov ugley [Features of allocation of technological groups in brands when calculating coal reserves]. Razvedka i okhrana nedr, 2017, no. 6 , pp. $42-48$.

5. Ivanov V.P. Promyshlenno-energeticheskaya klassifikatsiya dlya otsenki ratsionalnogo ispolzovaniya ugley [Industrial and energy classification to assess the rational use of coal]. Izvestiya vuzov. Fizika, 2015, no. 7, pp. 104-111.

6. Bielowicz B.A. New technological classification of low-rank coal on the basis of Polish deposits. Fuel, 2012, vol. 96, pp. 497-510.

7. Ivanov V.P., Torgunakov A.A., Okhotnikov K.V. The role of industrial and energy classification of fossil coals in the new classification of geological reserves of TPI. Subsoil use XXI century, 2017, no. 6, pp. 104-112. In Rus.

8. GOST 25543-2013. Ugli burye. kamennye $i$ antratsity. Klassifikatsiya po geneticheskim i tekhnologicheskim parametram [State Standard 25543-2013. Coals are brown, stone and anthracite. Classification by genetic and technological parameters]. Moscow, Standartinform Publ., 2014. 18 p.

9. Mazumder B. Coal structure and classification. Coal Science and Engineering, 2012, pp. 76-99.

10. Specifications guide Metallurgical coal. S\&P Global Platz-2019, November. pp. 6-8. Available at: https://www.spglobal.com/platts/ plattscontent/_assets/_files/en/our-methodology/methodologyspecifications/metcoalmethod.pdf (accessed 11 December 2019).
11. Guidelines for the application of the Classification of reserves of deposits and forecast resources of solid fossil fuels. Coals and oil shale. Available at: http://gkz-rf.ru/sites/default/files/docs/ met_rek_tpi_teo_ugli.pdf (accessed 19 September 2019).

12. Yuzvitsky A.Z. Metodika razvedki ugolnykh mestorozhdeniy Kuznetskogo basseyna [Methodology of exploration of coal deposits of the Kuznetsk basin]. Kemerovo, Knizhnoe izdatelstvo Publ., 1978. $235 \mathrm{p}$.

13. Ercegovac M. Genetic-industrial classification of brown coals in Serbia. Int. J. Coal Geol., 2006, vol. 68, Iss. 1-2, pp. 39-56.

14. CIM Definition Standards on Mineral Resources and Mineral Reserves. Prepared by the CIM Standing Committee on Reserve Definitions. Adopted by CIM Council, November 14, 2004. 185 p. Available at: http://www.crirsco.com/cim_definition_standards_2010.pdf (accessed 19 September 2019).

15. JORC standard and access to global financial markets. Overview and practical aspects. http://geomar.ru/articles/mineralresources/403-jorc-codex-and-classification-mineralresources.html (accessed 19 September 2019)

16. Eremin I.V., Bronovets T.M. Marochny sostav ugley $i$ ikh ratsionalnoe ispolzovanie: spravochnik [The vintage composition of coal and their rational use: reference book]. Moscow, Nedra Publ., 1995. 254 p.

17. Okhotnikov K.V., Ivanov V.P. Rol opornykh tochek razvedochnoy seti i dostovernost otsenki svoystv i kachestva ugley plastov [The role of reference points of the exploration network and the reliability of assessing the properties and quality of coal seams]. Razvedka i okhrana nedr, 2018, no. 6, pp. 21-25.

18. Okhotnikov K.V. The impact of the classification of coal reserves on the formation of the raw material base of a mining enterprise Coke and Chemistry, 2019, no. 9, pp. 8-12. In Rus

19. Code of Australasia for the compilation of reports on the results of exploration, mineral resources and ore reserves (JORC Code). Prepared by the Joint Committee on Reserves of the Australasian Institute of Mining and Metallurgy, Australian Institute of Geosciences and the Australasia Minerals Council (JORC). 2014. Available at: https://imcmontan.ru/files/jorc.pdf (accessed 19 September 2019). 
20. Khrustalyova G.K., Eremin I.V., Bronovets T.M. Kachestvo i napravlenie ispolzovaniya ugley. Printsipy sovremennoy promyshlennoy klassifikatsii ugley [The quality and direction of use of coal. The principles of the modern industrial classification of coal]. Ugolnaya baza Rossii [Coal base of Russia]. Moscow, Geoinformmark Publ., 2004. pp. 353-357.

Information about the authors
21. Mineral Reserves Reporting Standards. Available at: http://technology.infomine.com/reviews/ report-ingstandards/ welcome.asp?view=full. (accessed 11 July 2019).

Received: 16 January 2020.

Konstantin V. Ohotnikov, postgraduate student, National Research Tomsk Polytechnic University. 